\title{
Efficacy of Amnioinfusion for meconium stained liquor in labour in a rural hospital.
}

\author{
Dr. B. Shilpa Shivanna ${ }^{1}$, Dr. Lalitha Shivanna ${ }^{2}$ Dr. Ratnakar Rao ${ }^{3}$ \\ ${ }^{I}$ Associate Professor, Adichunchungiri Institute of Medical Sciences, Mandya District, India \\ ${ }^{2}$ Ex - Professor and Head, Adichunchungiri Institute of Medical Sciences, Mandya District, India \\ ${ }^{3}$ Ex - Professor, Adichunchungiri Institute of Medical Sciences, Mandya District, India.
}

\begin{abstract}
Incidence of meconium stained liquor is about 9.5\% -25\% of all deliveries. Incidence of placental and body staining is $5-10 \%$. It probably indicates previous episode of intrauterine hypoxia or a state of compensated fetal distress. $5-12 \%$ develop Meconium aspiration syndrome, a life threatening respiratory disorder which results from aspiration of meconium into the lungs and its perinatal morbidity and mortality ranges from $4 \%-40 \%$. prevention of meconium aspiration syndrome remains the major objective for obstetricians and neonatologists. Hence this study of amnioinfusion and its effect on maternal and perinatal morbidity and mortality in women with meconium stained liquor during labour was conducted. Objectives: To find out the efficacy of amnioinfusion in meconium stained liquor during labour. To study neonatal morbidity and mortality by assessing Apgar score at birth and NICU admission. Material And Methods : In this study 60 pregnant women in labour with meconium stained liquor were included.They underwent amnioinfusion and fetal outcome by apgar score at $1 \mathrm{~min}$ and $5 \mathrm{~min}$, admission to NICU were taken into consideration and analysed. Results: In our study 76.5\% had high risk factors like PIH ,IUGR, anaemia , 36\% had fetal heart variations and $42.8 \%$ needed NICU admission. $60 \%$ of the cases were multigravida with bishop's score $>6$. All had full term normal delivery. Other $40 \%$ were primigravidas of which $30 \%$ had LSCS and 10\% had instrumental deliveries. Average birth weight was $3 \mathrm{~kg}$. 41\% babies had 0-6 apgar score at 1 min and 59\% had 7-10 apgar at 5 minutes. depressed babies were admitted in NICU. There was 5\% perinatal mortality in our study. Conclusion: Amnioinfusion in active labour is associated with improvement in perinatal outcome most probably due to dilution in meconium and relief of oligohydramnios. There was a reduction in the rate of caeserean section for fetal distress and overall meconium aspiration syndrome and NICU admissions thereby reducing the perinatal morbidity and mortality.
\end{abstract}

Keywords: Amnioinfusion, Meconium aspiration syndrome, Caeserean section, perinatal outcome.

\section{Introduction}

Significance of meconium stained liquor is widely debated.Though $5-25 \%$ of all deliveries have meconium stained liquor ( Voltern 1687 ), Miller ${ }^{1}$ stated the presence of meconium in the amniotic fluid without FHR variation or fetal acidosis is not a sign of fetal distress per se. Leonard $\mathrm{JL}^{2} 1962$ stated that if meconium stained amniotic fluid ( MSAF ) alone is considered as an indicator of intervention then $42 \%$ extra caesereans would be necessary. There are three theories ${ }^{3}$ to explain fetal passage of meconium, one is in response to hypoxia , meconium is passed and signals fetal compromise. secondly it represents normal GIT maturation under neural control. Third it is associated with vagal stimulation from common but transient umbilical cord entrapment and resultant increased peristalsis and results in meconium stained liquor with FHR variation in $10-15 \%{ }^{4}, 5-12 \%$ develop Meconium aspiration syndrome (MAS), a life treatening respiratory disorder which contributes to neonatal morbidity and mortality.

Meconium in greek language means substance resembling poppy juice ${ }^{5}$ and contains GIT secretions ,bile juice ,cellar debris , amniotic fluid swallowed vernix caseosa, lanugo,blood .It can be early, late and old or thin, moderate and thick meconium based on timing and consistancy ${ }^{6}$ and takes $4-6$ hrs $^{7}$ to stain fetal body and placenta.Many studies have proved meconium stained liquor perse is a poor predictor of fetal asphyxia, acidosis and neonatal outcome ${ }^{8}$. Thick meconium with abnormal FHR increases chances of developing fetal acidemia to $88 \%$ and perinatal mortality ${ }^{8}$ to $32 \%, 30 \%$ at $40 \mathrm{wks}$ and $50 \%$ at $42 \mathrm{wks}$.

To prevent the deleterious effects of meconium aspiration , many measures have been suggested a) screening and monitoring of high risk cases as they are at risk of uteroplacental insufficiency b) oropharyngeal suction was advocated by carson and co before delivery of shoulders c) gastric suctioning of meconium stained infants. d) amnioinfusion i.e. clinical application of transcervical saline which was introduced by Miyazaki and co-workers ${ }^{9}$ as an intrapartum procedure for relief of variable deceleration and to dilute or washout thick meconium prophylactically and it initself will also accerelate the labour process. 


\section{Materials And Methods :}

This prospective study was done in Adichunchungiri institute of medical sciences over a period of 12 months and included 60 cases of booked and unbooked pregnant women in labour with meconium stained liquor. Abnormal presentations, intrauterine death ,previous caeserean , Antepartum haemorrhage, congenital abnormalities of the fetus were excluded from the study.Detailed history of demographic features , obstetric history, menstrual history, past and family history were taken. general physical examination was done. obstetrical examination for gestational age, lie ,presentation, position of the fetus ,FHR, duration, frequency of uterine contraction was done and documented. Pervaginal examination to assess Bishop's score ,pelvic adequecy to rule out Cephalopelvic disproportion was done. Admission test was taken for baseline FHR , any FHR variations.Basic investigations along with ultrasound for biophysical profile and doppler study were carried. After explaining the procedure, consent of the patient was taken .Under aseptic precautions red rubber catheter was intraduced transcervically into the uterine cavity, tip being kept above the presenting part . $500 \mathrm{ml}$ of normal saline was infused as bolus followed by $2-3 \mathrm{ml} / \mathrm{min}$ till delivery . [ Different authors followed different techniques- Adam 1989, Wenstrom 1989 , infused 1000ml over 20 -40 mins ; Hofmeyr 1998, Frazer 2005 used maximum of $800 \mathrm{ml}$ over $40 \mathrm{~min}$ and $3 \mathrm{ml} / \mathrm{min}$ to a total of $1500 \mathrm{ml}$ ]

Labour was augmented with oxytocin infusion 5 units in ringer lactate and continuous CTG monitoring was done .Progress of labour monitored with vigilance. Second stage of labour was cut short with Vacuum or outlet forceps in most of the cases.Active management of III stage was done with $250 \mathrm{mcg}$ of PGF $2 \alpha$ or $0.25 \mathrm{mg}$ of methergin or $800 \mathrm{mcg}$ of misoprostol rectally. Apgar score was assessed at 1 and $5 \mathrm{~min}$.

If any evidence of fetal distress or progress of labour was delayed, patient was taken for emergency LSCS . Outcome of the delivery was assessed by Meconium aspiration syndrome, NICU admissions, perinatal morbidity and mortality.

\section{Observation :}

In our study, age group varied from 18 yrs to 30 yrs. $40 \%$ were primy and $60 \%$ were multigravidas.

A . Relationship Of Meconium Stained Liquor With Maternal Age

\begin{tabular}{|l|l|l|}
\hline 18 -25years & 25 & $42 \%$ \\
\hline $25-30 y e a r s$ & 35 & $58 \%$ \\
\hline
\end{tabular}

Majority of the cases belonged to $25-30$ yrs age group.

B. Relationship Of Meconium Stained Liquor And Bishop's Score :

\begin{tabular}{|l|l|l|}
\hline$<6$ & 20 & $33 \%$ \\
\hline$>6$ & 40 & $66.5 \%$ \\
\hline
\end{tabular}

Majority of cases had bishop's score $>6$ and 33\%had $<6$ on admission

C. Associated Risk Factors :

\begin{tabular}{|l|l|l|l|}
\hline 1 & anemia & 10 & $16.5 \%$ \\
\hline 2 & Pre eclampsia & 15 & $25 \%$ \\
\hline 3 & IUGR & 6 & $10 \%$ \\
\hline 4 & Oligohydromnios & 6 & $10 \%$ \\
\hline 5 & PROM & 6 & $10 \%$ \\
\hline 6 & Post dated & 3 & $5 \%$ \\
\hline 7 & No obvious cause & 14 & $23.5 \%$ \\
\hline
\end{tabular}

In this study $76.5 \%$ had high risk factors and $23 \%$ were not associated with risk factors. 
D . Mode Of Delivery :

\begin{tabular}{|l|l|c|c|c|c|}
\hline \multicolumn{2}{|l|}{} & \multicolumn{2}{|l|}{$\begin{array}{l}\text { GROUP I } \\
\text { WITH AMNIOINFUSION }\end{array}$} & \multicolumn{2}{l|}{$\begin{array}{l}\text { GROUP II } \\
\text { WITHOUT AMNIOINFUSION }\end{array}$} \\
\hline $\begin{array}{l}\text { BISHOP'S } \\
\text { SCORE }\end{array}$ & & NO & $\%$ & NO & $\%$ \\
\hline$>6$ & FTND & 20 & $66.5 \%$ & 12 & $40 \%$ \\
\hline$<6$ & $\begin{array}{l}\text { INSTRUMENTAL } \\
\text { DELIVERY }\end{array}$ & 2 & $7 \%$ & 6 & $20 \%$ \\
\hline & LSCS & 8 & $26.5 \%$ & 12 & $40 \%$ \\
\hline
\end{tabular}

In our study group I with amnioinfusion had $66.5 \%$ full term normal deliveries, $7 \%$ had outlet forceps delivery and 3\% underwent LSCS ( with Bishop's score < 6 ) whereas group II without amnioinfusion had $40 \%$ FTND , 20\% had instrumental deliveries and 40\% underwent LSCS with poor Bishop's score and for fetal distress.

E. Correlation Between Msaf And Apgar Score :

\begin{tabular}{|l|c|c|}
\hline \multirow{4}{*}{1} & APGAR SCORE & NO. OF BABIES (\%) \\
\cline { 2 - 3 } & $0-6$ & $24(41 \%)$ \\
\cline { 2 - 3 } MIN & $7-10$ & $36(59 \%)$ \\
\hline \multirow{3}{*}{5 MIN } & $0-6$ & $12(21 \%)$ \\
\cline { 2 - 3 } & $7-10$ & $48(79 \%)$ \\
\hline
\end{tabular}

$41 \%$ of babies had apgar score $<6$ at $1 \mathrm{~min}$. Only $21 \%$ had low apgar at $5 \mathrm{~min}$. all babies who had low apgar score got admitted to NICU.

F. Correlation Between Msaf And Neonatal Morbidity And Mortality :

\begin{tabular}{|l|l|l|l|l|}
\cline { 2 - 5 } \multicolumn{1}{l|}{} & \multicolumn{2}{l|}{ Grovp I } & \multicolumn{2}{l|}{ Group II } \\
\hline morbidity & 1 & $3 \%$ & 12 & $40 \%$ \\
\hline mortality & - & - & 2 & $6.5 \%$ \\
& & & & \\
\hline
\end{tabular}

Neonatal morbidity was less in amnioinfusion group about $3 \%$ and mortality was nil, whereas $40 \%$ morbidity and $6.5 \%$ mortality was seen in the control group. 13 babies were admitted to NICU for one week out of which 2 babies in the control group died due to meconium aspiration syndrome.

\section{Discussion :}

Meconium stained amniotic fluid is always an enigmatic problem for which gynaecologist and neonatologist should be alert to prevent deadliest complication of MAS and its effect on multiple organs. 
Our study almost correlates with Pravin goud ${ }^{16}$ and ushakrishna, Miller, Paul meis ${ }^{17}$, Toshiotujikura where risk factors were present in $53 \%$ and in our study it was about $76.5 \%$ and $22.5 \%$ did not have any risk factors .

In our study with aminoinfusion $66.5 \%$ had FTND , 7\% had instrumental deliveries , $8 \%$ underwent LSCS and only $3 \%$ had meconium aspiration which correlates with S.K. Sandhu's study ${ }^{18}$ where $78.5 \%$ had FTND, 8.9\% had instrumental deliveries and 13.6\% underwent LSCS whereas in group II $40 \%$ had FTND, $20.5 \%$ had instumental deliveries whereas in group II $40 \%$ had FTND , 20.5\% had instrumental deliveries and $40 \%$ underwent LSCS which almost correlates with study by Narang et al ${ }^{19}$ where $54.2 \%$ had LSCS , 30.7\% had FTND and $11.8 \%$ had instrumental deliveries.

The percentage of Neonatal morbidity in our study is $3 \%$ in group I and $40 \%$ in group II .Mortality was nil in amnioinfusion group and $6.5 \%$ in group II . This almost correlates with studies conducted by S.K.Sandhu who had $20 \%$ morbidity and $6 \%$ mortality due to meconium aspiration syndrome.

\begin{tabular}{|c|c|}
\hline AUTHORS & NO. OF CASES WITH NEONATAL MORBIDITY \\
\hline Dooley et al & $21 \%$ \\
\hline Ross et al & $37 \%$ \\
\hline Gregory et al & $58 \%$ \\
\hline Our study & $\begin{array}{ll}3 \% & \text { ( GROUP I ) } \\
40 \% & \text { ( GROUP II ) } \\
\end{array}$ \\
\hline
\end{tabular}

\section{Conclusion}

Meconium aspiration syndrome is one of the major cause of neonatal morbidity and mortality .Advocating routine antenatal care, identification of risk factors for uteroplacental insuffiency , careful monitoring of patients antepartum, intrapartum fetal surveillance ,timely resusitation of the newborn by the paediatrician can decrease neonatal morbidity and mortality which can affect the psyche of the patient and of family perse. Different studies vary in views , but cochrane review by Hofmeyr GJ ,XUH 2010 puts forth that though there was no significant reduction in the primary outcomes of MAS, perinatal deaths/morbidity, there was certainly decrease in caeserean section for fetal distress, decrease in meconium below the vocal cords, decrease in NICU admissions and trend towards decrease in perinatal mortality.Though rare complications as cardiac failure, cord prolapse, abruption, amniotic fluid embolism , pyrexia have been reported ( Dibble 92' , Dragich 91' , Hofmeyr 96 ) benefits outweigh against these rare small risks.

Hence this feasible costeffective ( Moodley $\mathbf{J}$ et al ) procedure should become standard practice in the management of meconium stained liquor to reduce the morbidity and mortality.

\section{References}

[1]. Miller FC et al " significance of meconium during labour” Am J Obstet Gynaecol ,1975, 122 (5) : 573 - 579

[2]. Leonard JL Obstet Gynae ,1962,20: 320.

[3]. Cunnigham FG et al, Intrapartum Assessment, William Obstetrics, $20^{\text {th }}$ ed ,[ Stamford, Connecticut : Appleton and Lange , A Simon and Schuster company], 1997, $362-368$.

[4]. Wiswell TE, Fuloria Mamta , ' Management of meconium stained amniotic fluid ' , Clinics in perinatology , 26 ( 3 ) ,1999, 659 -665.

[5]. Bacsik RD, " Meconium aspiration syndrome " Pediatric clinics of N America , 24 (3), 1997 :463-477.

[6]. Arias Fernando, Birth asphyxia , Practical guide to high risk pregnancy and delivery , ( USA : Harcourt Brace and Company Asia PTE Ltd Mosby yr book, Inc 1992 ), $2^{\text {nd }}$ ed : $415-416$

[7]. Fujikura T and Klionsky B, “The significance of meconium staining “" Am. J .Obstet Gynecol ,121 (1); $1975: 45$ - 49.

[8]. Sundari N, Swamy AV,Anupama, " Meconium stained amniotic fluid : is it a cause of concern? " J Obs and Gynae Today ,3(8) ,1998; 469-472.

[9]. Sadovsky Y et al, ' Prophylactic amnioinfusion during labour complicated by meconium : A Preliminary report ' , Am J Obstet Gynecol , 61(3), 1989,613 - 617.

[10]. Wiswell TE, Tuggle JM, Tuener BS . Meconium aspiration syndrome have we made adifference? Pediatrics : 85,1990 , 715 - 721.

[11]. Dudley DKL , Assessment of fetus in utero, Oxor $n$ forte human labour and birth, $5^{\text {th }}$ ed, $596-597$.

[12]. Shaikh EM, Mehnood S, Shaikh MA, Neonatal outcome in meconium stained amniotic fluid - 1 year experience , journal of Pakistan Medical association ; 60, 2010, 711 -714.

[13]. Usta IM et al " The impact of a policy of amnioinfusion for meconium stained amniotic fluid " Ob and gynaec ,, 85 ( 2 ), 1995 : $237-240$.

[14]. Macri CG et al ,' Prophylactic amnioinfusion improves outcome of pregnancy complicated by thick meconium and oligohydramnios, Am J Obstet Gynaecol , 165(1), 1992 ,117-121.

[15]. Hofmeyr GJ , XUH, 'Amnioinfusion for meconium stained liquor in labour. Cochrane Database of systematic reviews 2010 ; issue 1.Art No CD000014; DOI :10.1002/14651858, Pub . 
[16]. Goud Pravin , Krishna Usha, " Significance of meconium staining amniotic fluid in labour " , J Obstet Gynae India , 39(4) ,1989 ; $523-526$.

[17]. Meis PJ et al , " Meconium passage - a new classification for risk assessment during labour" , Am J Obstet Gynecol , 1978 ; 131 : 509.

[18]. Sandhu SK et al, ' Critical evaluation of meconium staining of amniotic fluid and fetal outcome ' , J . Obstet Gynec . India , 1993:528- 531

[19]. Narang et al "Management of meconium stained amniotic fluid : A team approach " ,Indian pediatrics ,30, $1993: 9-13$

[20]. Peng TCC, Gutcher GR , Von Dorsten JP , ' A selective aggressive approach to the neonate exposed to meconium stained amnioticfluid ' , Am J Obs Gynaecol , 175 (2), 1996, 296 -300.

[21]. Wiswell TE et al, " Delivery room management of the apparently vigorous meconiumstained neonate ,results of the multicenter , International collaborative Trial " pediatrics, 105 (1),2000, 1 -7.

[22]. Katz VL, Bowes WA, " Meconium aspiration syndrome. Reflexions on a murky object " , Am J Obstet Gynecol, 166(1), 1992, $171-179$. 